\title{
Learning Media on Mathematical Education based on Augmented Reality
}

\author{
Kalaphath Kounlaxay ${ }^{1}$, Yoonsik Shim ${ }^{1}$, Shin-Jin Kang ${ }^{2}$, Ho-Young Kwak ${ }^{3}$, and Soo Kyun Kim ${ }^{3 *}$ \\ ${ }^{1}$ Department of Game Engineering, Paichai University, Daejeon, South Korea \\ [e-mail: kk_koun@hotmail.com, ysshim@pcu.ac.kr] \\ ${ }^{2}$ School of Games, Hongik University, 2639 Sejong-ro, Jochiwon, Sejong, Korea \\ [e-mail: directx@ @ongik.ac.kr] \\ ${ }^{3}$ Department of Computer Engineering, Jeju National University, South Korea \\ [e-mail: kwak@jejunu.ac.kr,kimsk@jejunu.ac.kr] \\ *Corresponding author: Soo Kyun Kim
}

Received September 3, 2020; revised October 30, 2020; accepted November 18, 2020;

published March 31, 2021

\begin{abstract}
Modern technology offers many ways to enhance teaching and learning that in turn promote the development of tools for educational activities both inside and outside the classroom. Many educational programs using the augmented reality (AR) technology are being widely used to provide supplementary learning materials for students.

This paper describes the potential and challenges of using GeoGebra AR in mathematical studies, whereby students can view 3D geometric objects for a better understanding of their structure, and verifies the feasibility of its use based on experimental results. The GeoGebra software can be used to draw geometric objects, and 3D geometric objects can be viewed using AR software or AR applications on mobile phones or computer tablets. These could provide some of the required materials for mathematical education at high schools or universities. The use of the GeoGebra application for education in Laos will be particularly discussed in this paper.
\end{abstract}

Keywords: GeoGebra, Geometry, Mathematic, Learning Media, Augmented Reality 


\section{Introduction}

Academically, while mathematics is a difficult subject for most students, it also helps develop the ability to think logically. There are many systematic crises and analyses in mathematics, one of which is regarding the calculation of area. Geometry of space is one such branch of mathematics, where 3D objects are studied. Additionally, mathematics provides useful graphics capabilities, where a $3 \mathrm{D}$ vector is represented by a triple of number $\{x, y, z\}$, while presenting a large number of real-world applications [1]. Such an entity can describe a point in a 3D space. Though a vector can be presented as a row vector, most computer graphic books use column vectors, in what is known as the primary column form [2], because there are many properties of $3 \mathrm{D}$ vectors that are direct extensions of those of $2 \mathrm{D}$ vectors.

Currently, technology is evolving rapidly. One of the elements of technological progress is the advent of Industry 4.0, which emphasizes on digital learning [3]. Therefore, many types of technologies are under development, one of which is the AR technology.

Though the use of AR in education is new, it has advanced rapidly. Mathematical concepts, especially in geometry, are sometimes difficult to understand as students are required to visualize in 3D. Therefore, virtual reality (VR) can be used effectively to improve the learning process by stimulating curiosity and increasing students' motivation [4]. Azuma [5] provides a good definition of AR, namely the transformation of VR. AR allows users to see the real world with virtual objects that comprise the real world. Users can also see geometric virtual objects such as 3D cubes or cones overlaid on images of $2 \mathrm{D}$ cubes or cones. This can support students' visualization, in turn facilitating better understanding.

\section{Literature Review}

This section will describe the fundamental knowledge required for this research, including concepts, principles, and methods related to application development. An important purpose of the educational environment is to introduce social interaction between users in the same physical area. The integration of mathematical software, such as GeoGebra programs, enhances students' learning of geometric concepts [6]. In the literature, researchers in various fields, such as computer science and educational technology, have provided different definitions for AR [7].

\subsection{Learning Media}

Learning media transfer knowledge from the teacher to the students by engaging student's attention on the contents of the lesson. There are many types of learning media, such as pictures, transparencies, slides, audio and video recording, multimedia, and certain types of hardware or software media. In general, media provide a tool that can be used as a channel to achieve teaching objectives [8-9]. Therefore, for students, learning media are expected to facilitate the understanding of the content or concepts defined by the teacher.

\subsection{Augmented Reality}

$\mathrm{AR}$ is a new technology that blends the actual and virtual worlds by using 3D object replacement techniques or a human-machine interface [10]. It simulates the real-world experience for the user to see, smell, hear, and feel. Furthermore, virtual technology enables the user to join in the activity. It has emerged that AR can be adapted in various ways to support entrepreneurs. Presumably, it will modify the way we perceive the world around us. Essentially, this will add graphics layers and other sensory enhancements to the natural world 
in real time [11]. AR places virtual objects in real-time environments that can be seen through different display objects and transforms the environment into a digital interface [12]. The working concept of the AR is shown in Fig. 1.

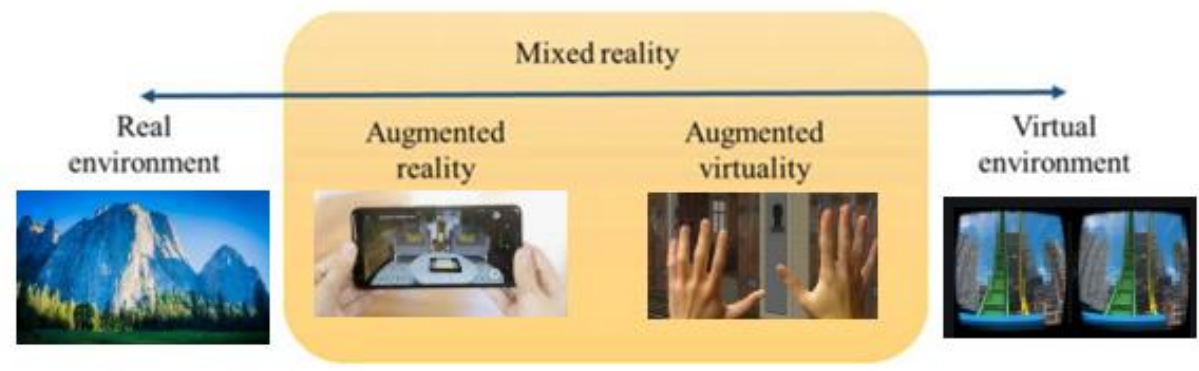

Fig. 1. Reality-virtuality Continumm (Milgram \& Kishino 1994)

Fig. 1 shows that the mixed reality (MR) spectrum encompasses all possible changes and compositions of real and virtual objects. On the far left is a real environment without any computer rendering. At the far right of the spectrum is a virtual environment, where everything is created using computers.

\subsection{GeoGebra Augmented Reality}

GeoGebra AR displays graphs and 3D objects in real-world environments and connects the real world with the abstract math world [13]. It also can place mathematical objects on any surface, allow the user to walk around them, and take screenshots from different angles. With GeoGebra's feature, students can now model virtual 3D objects on real-world objects directly in AR applications [14]. Using AR's feature, students visualize mathematical objects, such as prisms, that in real life can be connected to a box. It is also possible to walk into the virtual box and take screenshots from different perspectives, which is a unique experience for students [15]. The GeoGebra augmented reality includes the following features:

- Create 3D mathematical objects that appear and can be placed on a desk, floor, or any flat surface.

- Activities that lead to the discovery of mathematics in the real environment by taking screenshots from different perspectives.

- Explore the potential of AR in learning and teaching mathematics.
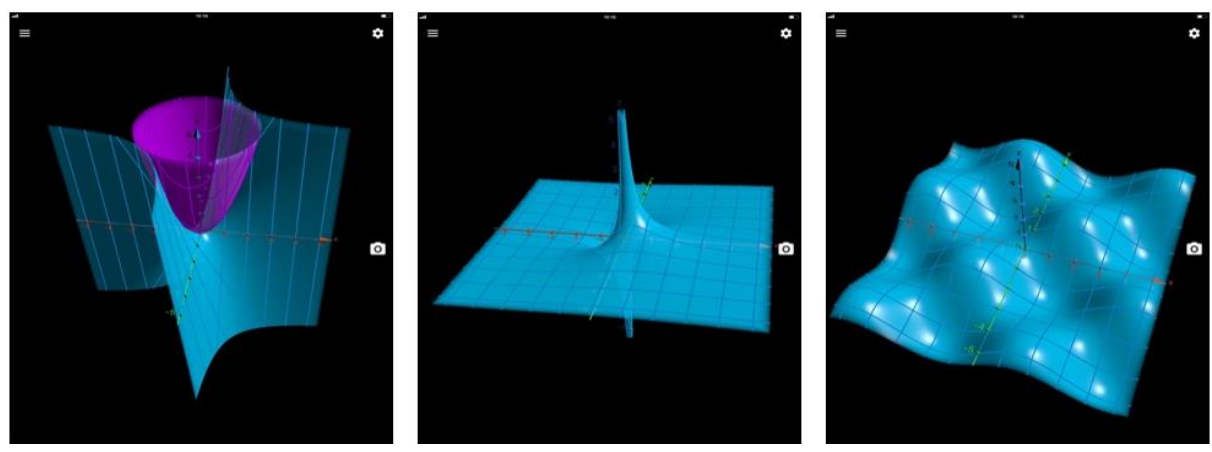

Fig. 2. GeoGebra Augmented Reality Apps 


\subsection{Geometry}

Geometry is a basic course in mathematical education that focuses on the description and analyses of 2D and 3D shapes using visualization and spatial reasoning, and uses mathematical models (geometric models) to solve problems. Currently, a variety of technologies are available in geometric teaching to create learning management media. According to [16], the development of a technology-based media for improving students' algebra learning outcomes identified that school was a factor affecting their ability to learn; the qualitative analysis of students' writing and digital documents during the test reaffirmed the quantitative results that the effective use of a variety of technologies improves students' understanding of algebraic content.

\subsection{GeoGebra Software}

At the end of 2014, GeoGebra developed version 5.0 that included 3D graphics to facilitate the study of 3D geometry by offering the ability to create various shapes that can be unfolded, cut and viewed from multiple perspectives. The course for creating teaching materials using GeoGebra software is suitable for teachers and educational personnel [17], where teachers must remember that the aim should be to provide students with skills that enable them to analyze both the nature and properties of numbers and geometric shapes. Spatial visualization abilities are enhanced in the process of developing arguments to connect and use the system for localization [18]. There is an increasing demand to develop teaching materials that provide greater clarity to learners.

GeoGebra is an online mathematical program that can create graphs and various geometric shapes, can support up to 70 languages, and is able to store work on Google Drive. It is also a freely available mathematical software for all levels of mathematical education, such as geometry, algebra, graphs, and calculus, and is the top service provider of dynamic mathematics programs used to support science, technology, engineering, and mathematics (STEM), education, and innovation in teaching and learning worldwide. The utilization of STEM methods in mathematics teaching can improve the quality of learning, which will in turn enhance the academic ability of students [19]. Knowledge of technology is inseparable from content, and good mathematical education requires the comprehension of how technology relates to education and mathematics [20]. Dental technology and mathematics emphasize on applying knowledge to solve real-life problems, including the development of new processes or products that are beneficial to working life and are innovative in the area of learning management in mathematics around the world.

In computer graphics, geometric objects usually comprise lines, polygons, and polyhedra. Such objects exist in a 3D world and have properties that can be described using concepts such as length and angle [21]. Generally, in the field of 3D geometric learning, GeoGebra is a powerful and easy-to-use mathematical teaching software that is suitable for learning and teaching at all levels of education [22]. It can be used for learning geometry, algebra, tables, calculations, graphs, calculus, and statistics, and most importantly, is an open-source software that is available free of cost from http://www.geogebra.org to use with teaching and learning media. GeoGebra's latest feature for automatic geometric fact management is the basis for the automatic development of mathematical layers on the photographs of the monuments taken by our smartphones as we walk through various locations [23]. The software can be used for creating images and 3D models within the program itself, or worksheets created by others that are shared on the GeoGebra web server can be used. These worksheets can be downloaded for 
free into offline GeoGebra applications for iOS, Android, Windows, Mac, Chromebook, and Linux. Millions of people around the world use GeoGebra to learn mathematics and science.

$\begin{aligned} & \text { Graphing Calculator } \\ & \text { Graph functions, investigate equations, and plot data } \\ & \text { with our free graphing app }\end{aligned}$
DOWNLAD $\begin{aligned} & \text { Geometry } \\ & \text { Construct circles, angles, transformations and more } \\ & \text { with our free geometry tool }\end{aligned}$

Fig. 3. Offline GeoGebra Apps

\section{Methods}

In this study, the use of GeoGebra software in an open class to create 3D geometric objects for AR apps was proposed. Teachers will use GeoGebra applications for mathematical education and problem solving. After the teaching and learning process, students will be assessed regarding their understanding of geometric patterns, gained from the classroom.

\subsection{System Overview}

The proposed system comprises three parts: a GeoGebra web application, GeoGebra web server and mobile application, as shown in Fig. 4.

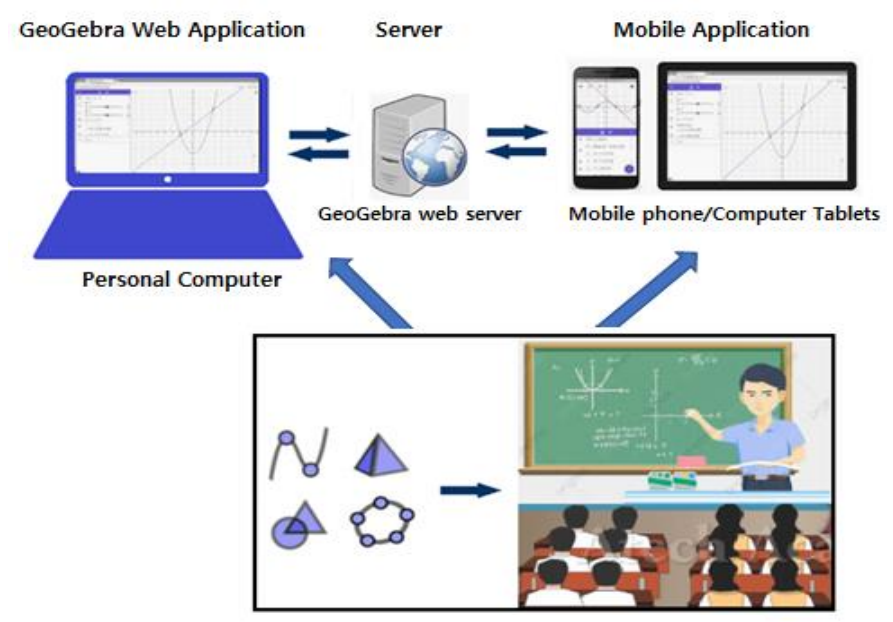

Fig. 4. System Overview 
Fig. 4 shows the GeoGebra web application, which has a remote login ability to the GeoGebra web server or URL http://www.geogebra.org via a personal computer or mobile phone for the creation of a user account and implementation of the online version. The users can then download the GeoGebra software and create their profile to use the GeoGebra Library (GGB Library), where new geometry models can be created and data models can be modified, as shown in Fig. 5.

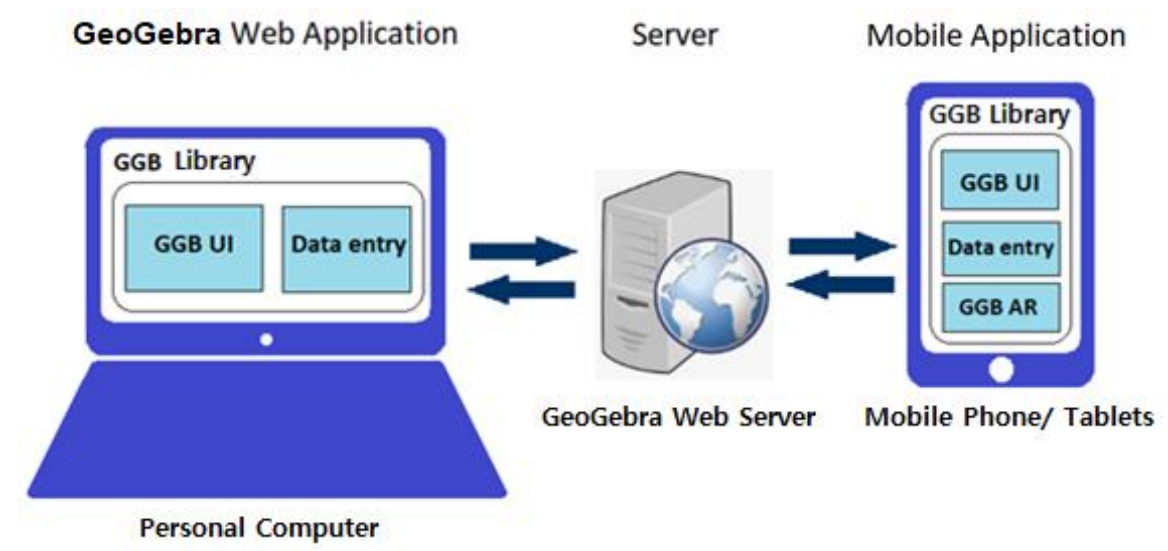

Fig. 5. GGB Library

\subsection{System Activity Diagram}

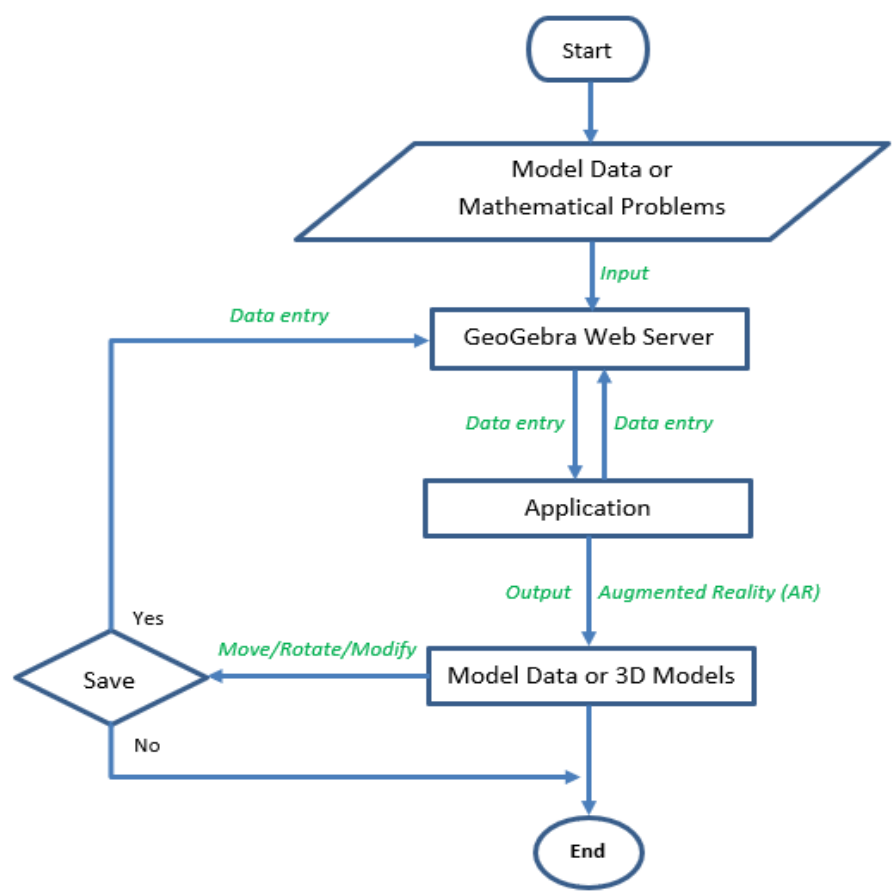

Fig. 6. System Activity Diagram 
Fig. 6 shows the system activity diagram, where the first step is the preparation of model data or input of data into the GeoGebra program for solving the mathematical problem. The information is then sent to the GeoGebra web application and is available for the logged-in user to create or manipulate the application depending on the equation models.

\subsection{Create GeoGebra Profile}

The user must first login, which can be accomplished in multiple ways, including Google, Office 365, Facebook, and Twitter, as all of these web-portals are currently affiliated, and the associated profile login information can be used. For this study, login with a Facebook profile was used, as most people have existing Facebook profiles. Once logged in, the screen appears as depicted in Fig. 7.

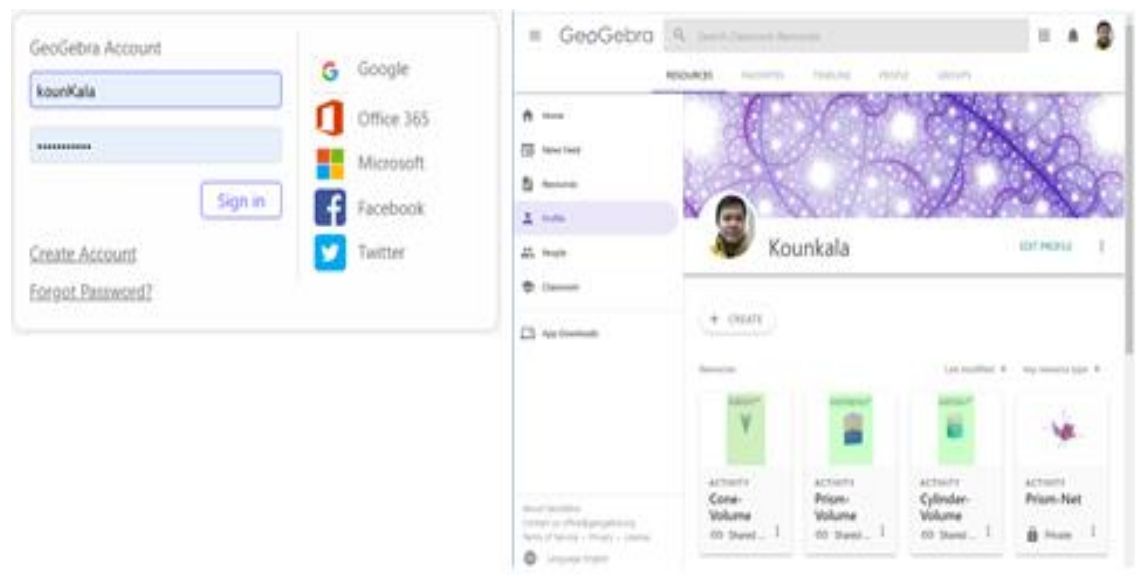

Fig. 7. GeoGebra Profile

\subsection{Geometric Object Models}

The GeoGebra application allows students to connect mathematics to the world around them, explore explanations, and apply different concepts and practical skills. The app facilitates the visualization and manipulation of mathematical objects and switches between $2 \mathrm{D}$ and $3 \mathrm{D}$ functionalities. In this section, various 3D geometric objects have been designed as 3D models, where each 3D model represents a type of solid 3D shape. Specific solid 3D shapes, such as a cube, cylinder, cone, pyramid, and prism, which are used to design 3D geometric objects, were selected to create GeoGebra applications for mathematical education, as depicted in Table 1.

Table 1. Solids Shapes Template

\begin{tabular}{|l|c|c|c|}
\hline Types & 3D Shapes & Shapes Net & Formulas (Volume of shapes) \\
\hline Cube & &
\end{tabular}




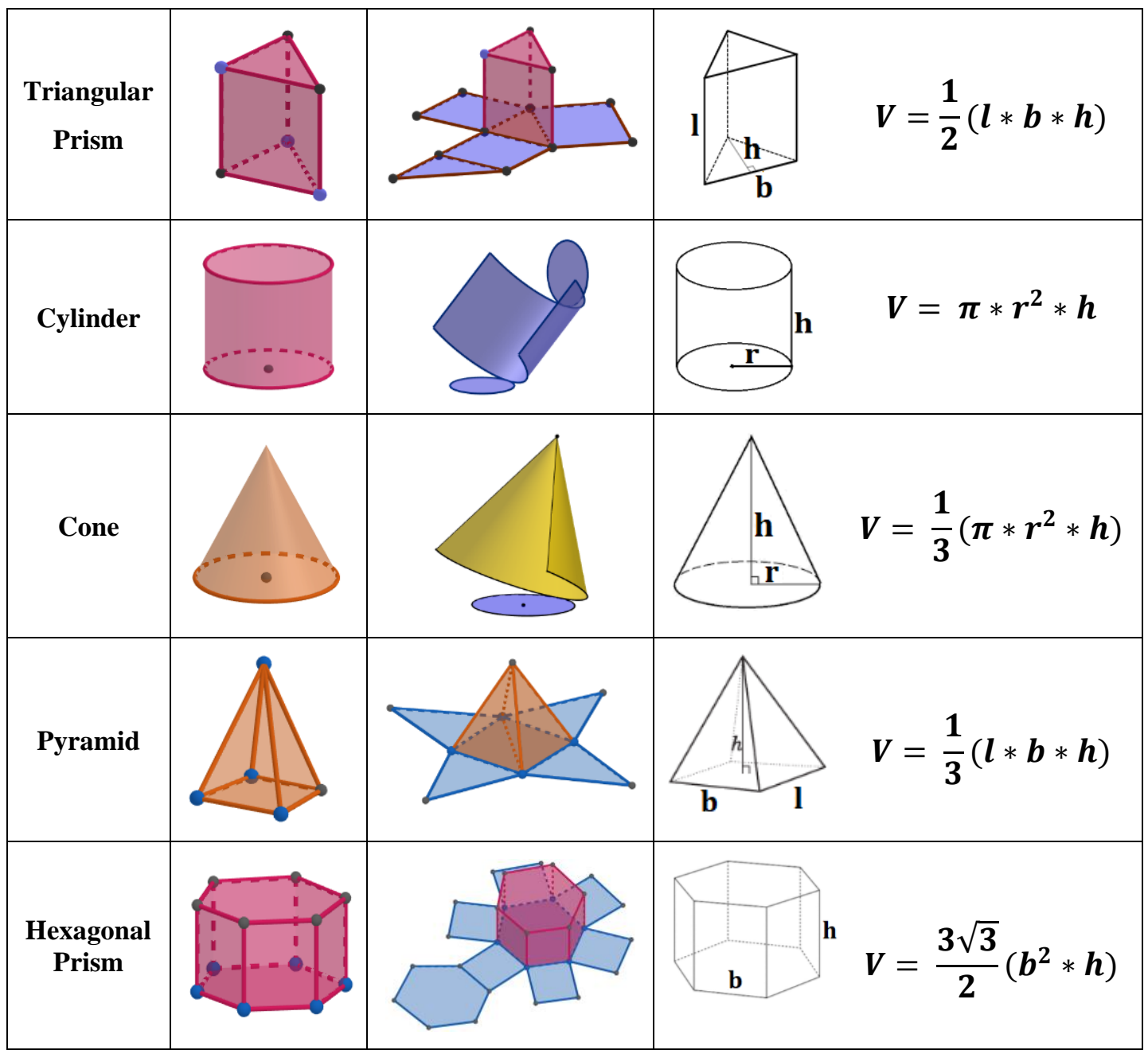

\section{Experiments and Teaching Methods}

\subsection{Experimental Process}

For this experiment, use of the GeoGebra software to create a 3D geometric model was proposed and the GeoGebra Script was used to implement the same, as shown in Fig. 8 where (a) depicts the installation of the GeoGebra 3D application on mobile devices. (b) shows the 3D model of a rectangle after data has been input into GeoGebra. (c) shows GeoGebra AR without a marker. (d) shows the calculation of the volume of a cube with a high-value slider and its AR. (e) shows the calculation of the volume of a triangular prism with a high-value slider and its AR. (f) shows the calculation of the volume of a cylinder with radius and highvalue sliders and its AR. ( $\mathrm{g}$ ) shows the calculation of the volume of a cone with radius and high-value sliders and its AR. (h) shows the calculation of the volume of a pyramid with highvalue sliders and its AR. (i) shows the calculation of the volume of a hexagonal prism with high-value sliders and its AR. 


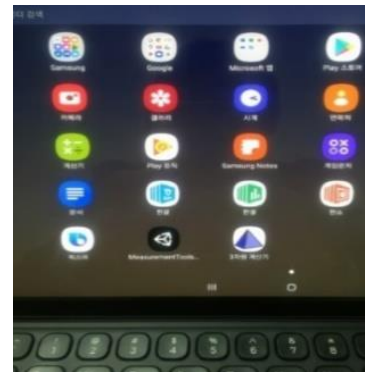

(a)

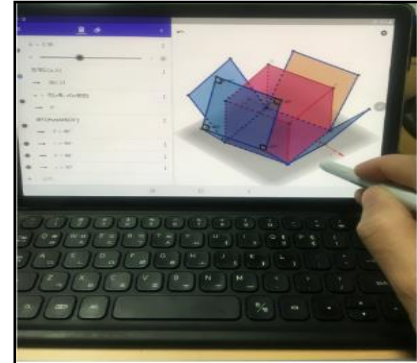

(b)

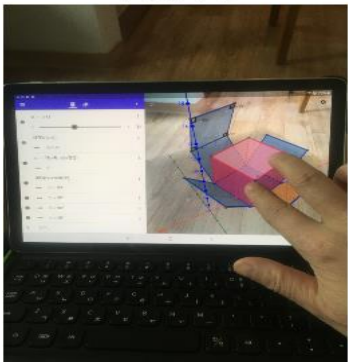

(c)
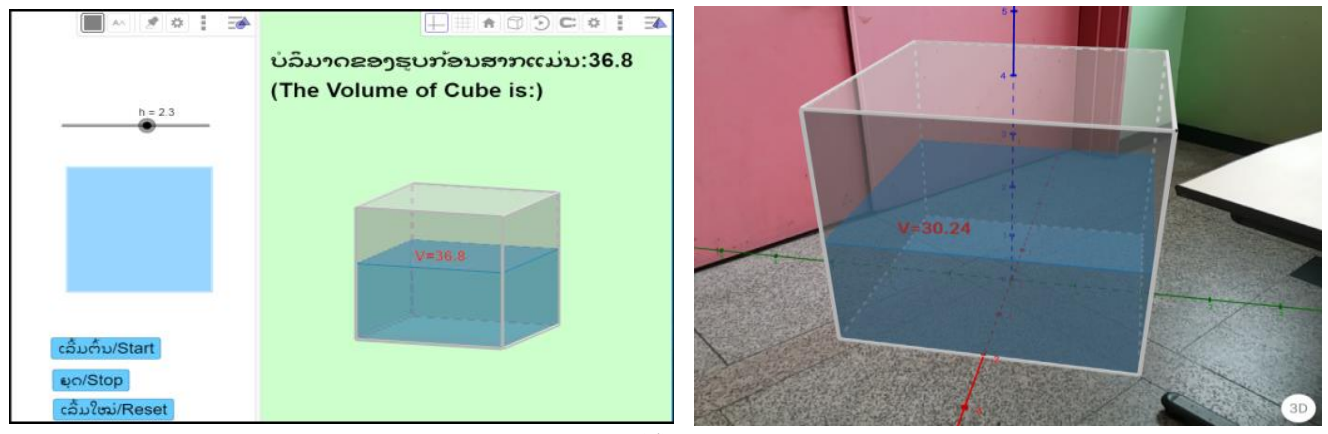

(d)

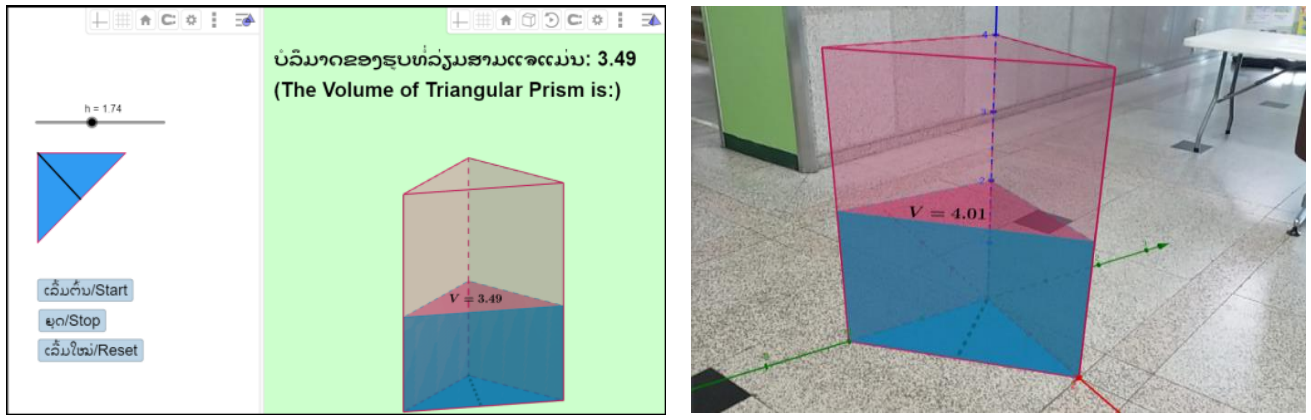

(e)

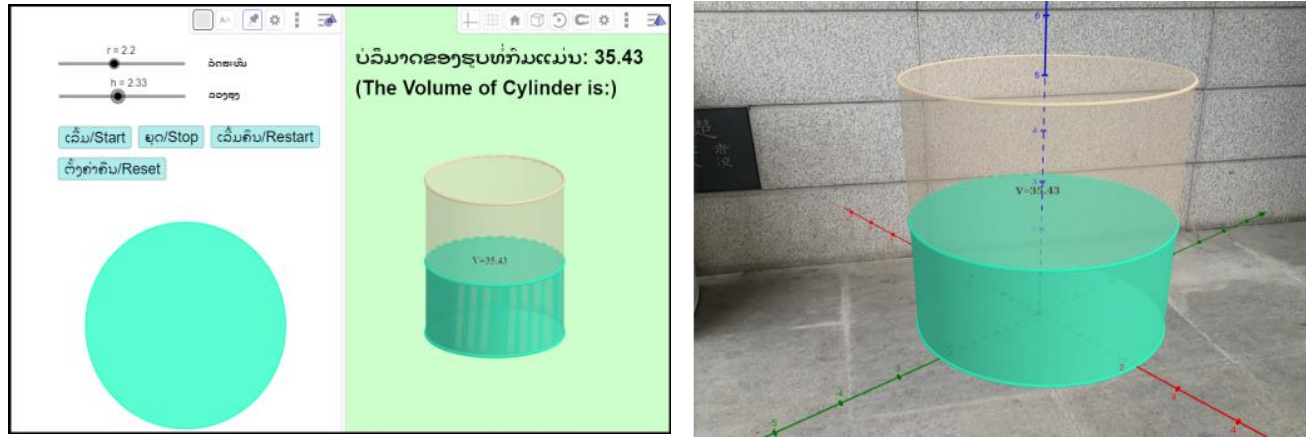

(f) 


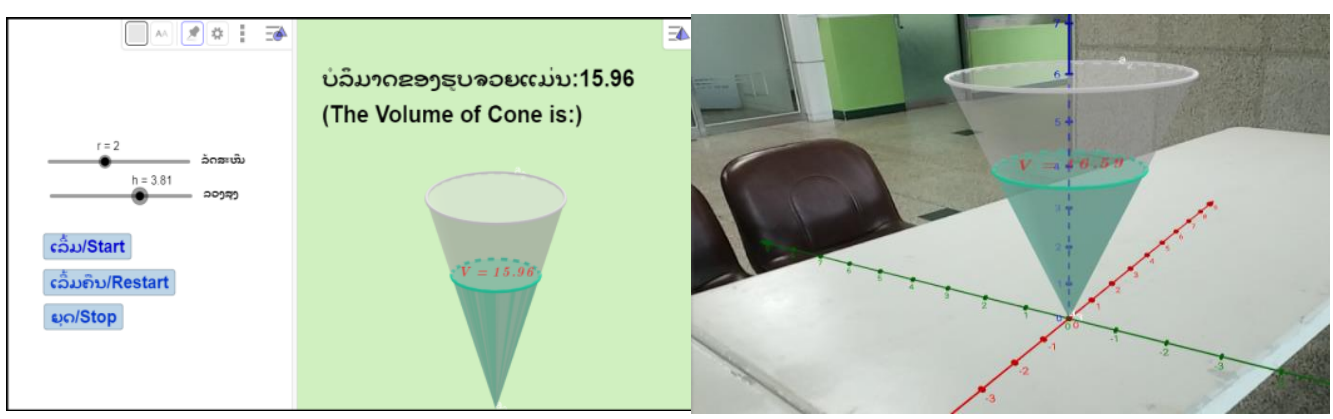

$(\mathrm{g})$
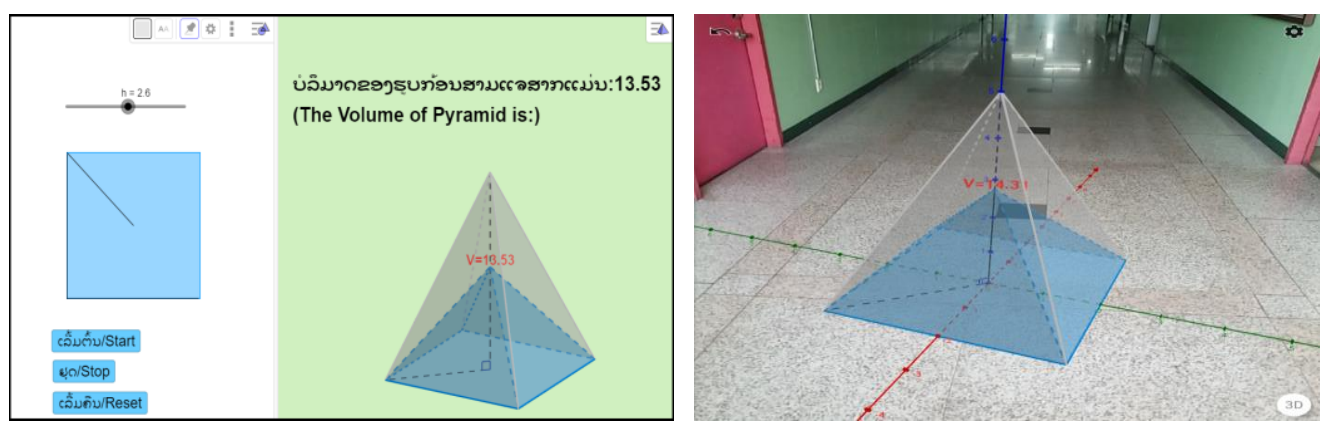

(h)
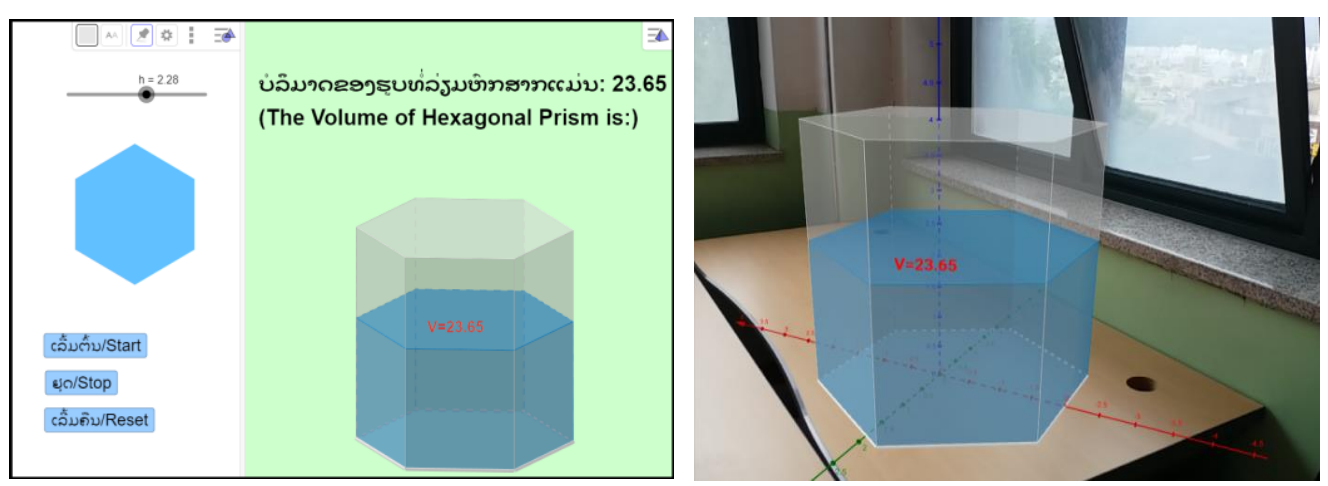

(i)

Fig. 8. Results

\subsection{Teaching Methods}

In this section, two types of teaching methods are proposed. The online versions were prepared for the participating teachers and the offline versions (open classroom) were prepared for the participating students, all of whom belong to the Faculty of Engineering, Souphanouvong University in Laos. First, a distance learning session was offered to the participants via a Zoom meeting and URL: https://www.geogebra.org/u/kounkala was used for the introduction. Ten teachers participated in the online classroom, as shown in Fig. 10, for a real-time interaction with various $3 \mathrm{D}$ geometric object models that were created using GeoGebra programs, as shown in Fig. 8 above. 


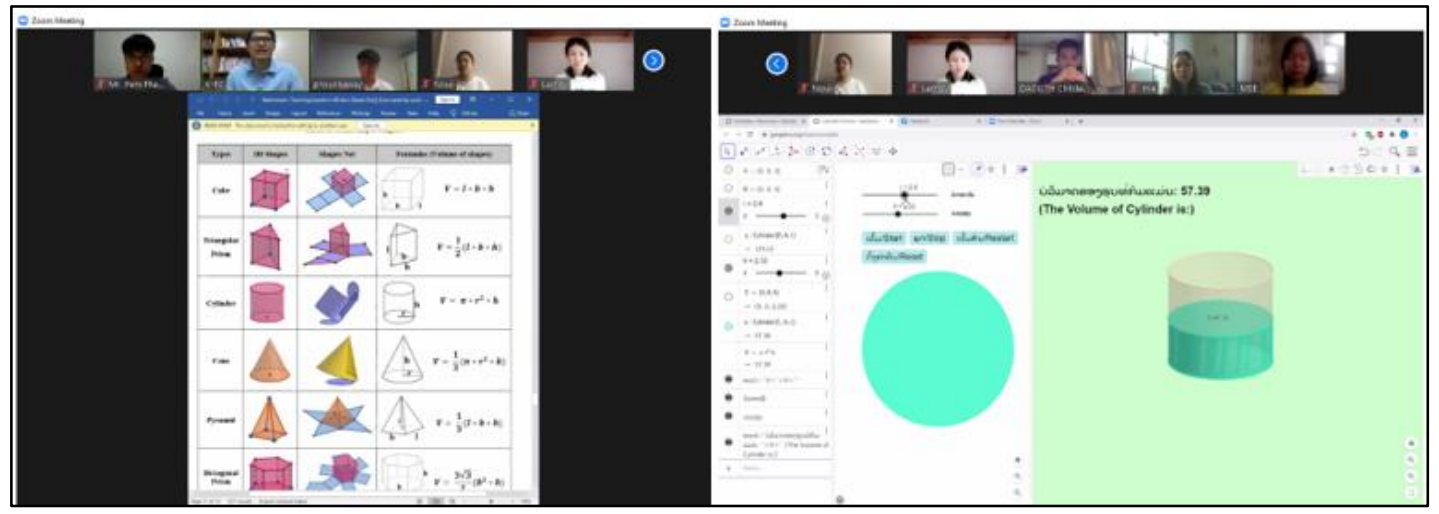

Fig. 9. Presenting GeoGebra Application through Zoom Meeting

For the second method, teachers were provided with a classroom that included a number of students, as shown in Fig. 10, and used the GeoGebra application that was developed to introduce and teach during class. At the same time, students could also login to use the applications out-of-school.
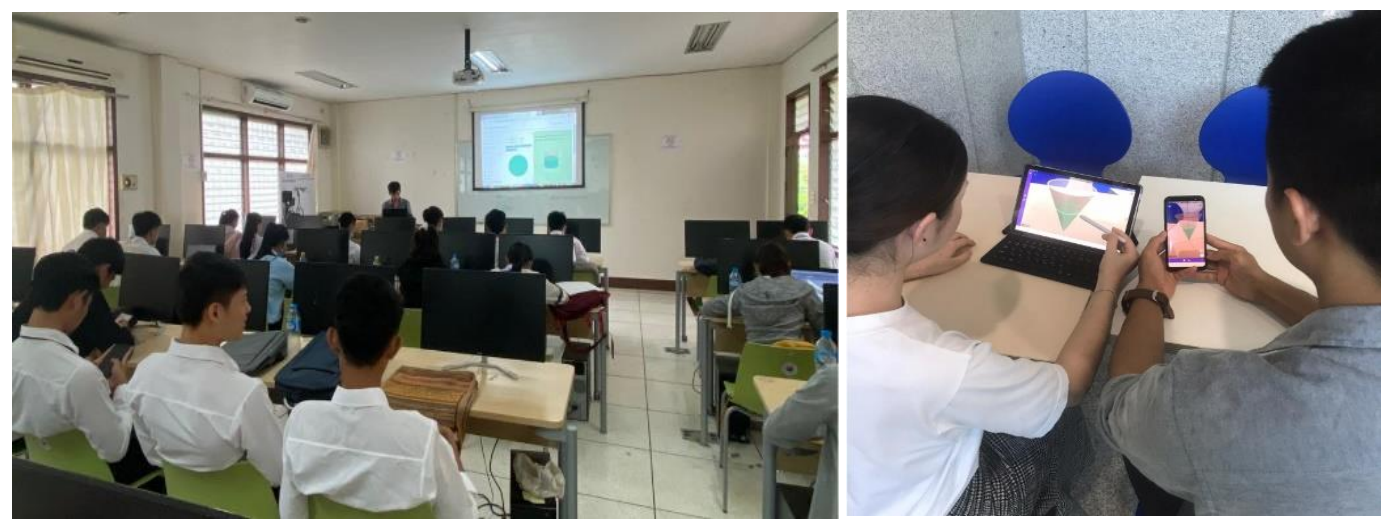

Fig. 10. Using GeoGebra Apps in the Classroom

Fig. 10 depicts the classroom teaching method using GeoGebra programs. The teacher demonstrated the use of GeoGebra 3D models that were created and stored in resources and shared via the link URL: https://www.geogebra.org/m/euvsjtbx that was provided by the GeoGebra web server. Students could also login to use those applications through their mobile phones or computer tablets using the GeoGebra classroom ID or URL. In this teaching and learning method, students could manipulate or create 3D models and test the model's behavior in response to diverse parameters. Lastly, after the teaching and learning process, students were assessed based on their understanding of the geometric patterns and the learning experience from the classroom.

\subsection{Assessment}

For the assessment, teachers created small tests or questionnaires to explore students' conceptual knowledge and understanding. This study involved a survey and utilized 
quantitative data to investigate Lao undergraduate students' attitudes towards the use of GeoGebra applications in teaching and learning. It measured students' opinions regarding their performance after taking the class that focused on learning 3D geometry through the use of GeoGebra applications. There are 40 students participated in this learning and answered the questionnaires or survey form. A questionnaire using 5-point Likert scale: 5 for strongly agree, 4 for agree, 3 for neutral, 2 for disagree, and 1 for strongly disagree, was used. The evaluation criteria of the questionnaire responses are: $1.00-1.49$ is strongly disagree; $1.50-2.49$ is disagree; 2.50-3.49 is neutral; 3.50-4.49 is agree; $4.50-5.00$ is strongly agree. The results from the survey responses and the analysis of quantitative data are shown in Table 2.

Table 2. The Students' opinions toward their success after taking the class on mathematic education through the use of 3D GeoGebra geometry

\begin{tabular}{|c|c|c|}
\hline Statements & Mean & Level \\
\hline 1. I found the GeoGebra interface easy to learn. & 4.04 & Agree \\
\hline $\begin{array}{l}\text { 2. Once I learned the GeoGebra interface, I found the } \\
\text { image is beautiful, clear and realistic. }\end{array}$ & 4.28 & Agree \\
\hline $\begin{array}{l}\text { 3. Once I learned the GeoGebra interface, I found } \\
\text { object manipulation easy and intuitive to use. }\end{array}$ & 3.95 & Agree \\
\hline $\begin{array}{l}\text { 4. I prefer the GeoGebra application that is helpful to } \\
\text { solve math problems. }\end{array}$ & 4.47 & Agree \\
\hline $\begin{array}{l}\text { 5. I prefer the new interface to a mouse and keyboard } \\
\text { interface. }\end{array}$ & 3.76 & Agree \\
\hline 6. I was able to create the $3 \mathrm{D}$ objects that I wanted. & 3.47 & Neutral \\
\hline $\begin{array}{l}\text { 7. I would use the system myself in my home or out } \\
\text { of school. }\end{array}$ & 3.38 & Neutral \\
\hline 8. I would recommend the system to friends. & 4.42 & Agree \\
\hline $\begin{array}{l}\text { 9. Overall, I enjoyed the experience, and learning } \\
\text { more engaging than studying with } 2 \mathrm{D} \text {. }\end{array}$ & 4.57 & Strongly agree \\
\hline 10. I think I am able to improve my learning skill. & 4.52 & Strongly agree \\
\hline
\end{tabular}

In Table 2, the mean scores of 3.47 and 3.38 (neutral) indicate that students who were part of this survey were unsure of their ability to create 3D objects using the GeoGebra application on their own. Using GeoGebra AR in the classroom or outside school requires access to certain resources, and some students may not have a smartphone that supports AR applications. Moreover, some students in Laos are from rural areas and may face challenges with receiving adequate internet speeds. The mean scores of 4.57 and 4.52 conclusively prove that studying with the 3D GeoGebra application was enjoyable to the students and more engaging than studying in 2D or with traditional teaching and learning methods. Additionally, students were able to improve their learning skills. 


\section{Conclusion}

With the help of AR applications, teachers can enhance the learning process with a high potential for better understanding, thereby increasing student engagement and motivation. It would be more interesting if the teacher could use the pages of books or worksheets of the content being studied, to create a variety of AR geometry models that enable students to use their mobile phones or computer tablets to visualize the $3 \mathrm{D}$ objects being studied. The objects move off the pages in the book and can be seen as virtual objects in 3D from different angles. This is a new method of learning and teaching being offered in Laos. In particular, it can be used for teaching mathematics at high schools or universities. Two types of teaching methods are proposed here, the online version, such as distance learning via a Zoom meeting, and the classroom version for mathematics education, which were designed with teachers and students at the Faculty of Engineering, Souphanouvong University in Laos. In this teaching method, students can manipulate or create 3D models and test the behavior of the models according to the situation. Therefore, education with the GeoGebra application can transform learning and make it more engaging, interactive, and enjoyable than studying with 2D.

\section{Acknowledgement}

This work was supported by the Research Grant of Jeju National University in 2020.

\section{References}

[1] T. Wickham-Jones, Mathematica Graphics Techniques \& Applications, Santa Clara, California, USA: TELOS/Springer-Verlag Press, 1994. Article (CrossRef Link)

[2] T. Akenine-Moller, E. Haines, and N. Hoffman, Real-Time Rendering, $2^{\text {nd }}$ Edition, Maimi, USA: Taylor \& Francis Press, 2002. Article (CrossRef Link)

[3] M. Crnjac, L. Veza, and N. Banduka, "From Concept to the Introduction of Industry 4.0," International Journal of Industrial Engineering and Management, vol. 8, No. 1, pp 21-30, 2017. Article (CrossRef Link)

[4] M. Roussos, A. Johnson, T. Moher, J. Leigh, C. Vasilakis, and C. Barnes, "Learning and Building Together in an Immersive Virtual World," Presence: Teleoperators \& Virtual Environments, vol. 8, no. 3, pp. 247-263, 1999. Article (CrossRef Link)

[5] R. T. Azuma, "A survey of augmented reality," Presence: Teleoperators \& Virtual Environments, vol. 6, no. 4, pp. 355-385, 1997. Article (CrossRef Link)

[6] K. K. Bhagat and C. Y. Chang, "Incorporating GeoGebra into Geometry learning-A lesson from India," Eurasia Journal of Mathematics, Science \& Technology Education, vol. 11, no. 1, pp. 7786, 2015. Article (CrossRef Link)

[7] H. K. Wu, S. W. Lee, H. Y. Chang, and J. C. Liang, "Current status, opportunities and challenges of augmented reality in education," Computers \& Education, vol. 62, pp. 41-49, 2013.

Article (CrossRef Link)

[8] O. D. Omodora and E. I. Adu, "Relevance of Educational Media and Multimedia Technology for Effective Service Delivery in Teaching and Learning Process," IOST Journal of Research \& Method in Education, vol. 4, no. 2, pp. 48-51, 2014. Article (CrossRef Link)

[9] L. D. Pratama, "Development of Learning Media for Mathematics Edutainment Based on Problem Solving Oriented with Interest in Learning and Understanding of Concepts of Building Material in Middle School," Universitas Negeri Yogyakarta, Yogyakarta, 2018.

[10] J. Jerald, The VR book human-centered design for virtual reality, Morgan \& Claypool Publishers, 2016. Article (CrossRef Link) 
[11] M. Agrawal, A. Kulkarni, S. Joshi, and N. Tiku, "Augmented Reality," International Journal of Advance Research in Computer Science and Management Studies, vol. 3, no. 2, 2015. Article (CrossRef Link)

[12] V. Agrawal and J. Patel, "A Review: Augmented Reality and Its Working," International Journal of Engineering and Technology, vol. 4, no. 5, 2017. Article (CrossRef Link)

[13] M. Tomaschko and M. Hohenwarter, "Augmented Reality in Mathematics Education: The Case of GeoGebra AR," Augmented Reality in Educational Settings, pp. 325-346, 2019. Article (CrossRef Link)

[14] A. Trappmair and M. Hohenwarter, "Driving augmented reality: geogebra's new AR features in teaching mathematics," in Proc. of Conference on Technology in Mathematics Teaching-ICTMT 14, 2019. Article (CrossRef Link)

[15] N. Budinski and Z. Lavicza, "Teaching Advanced Mathematical Concepts with Origami and GeoGebra Augmented Reality," in Proc. of Bridges 2019 Conference Proceedings, pp. 387-390, 2019. Article (CrossRef Link)

[16] A. Jupri, P. Drijvers, and M. Heuvel-Panhuizen, "Improving Grade 7 Students' Achievement in Initial Algebra Through a Technology-Based Intervention," Digital Experiences in Mathematics Education, vol. 1, pp. 28-58, 2015. Article (CrossRef Link)

[17] C. C. Meng and N. Idris, "Enhancing students' geometric thinking and achievement in solid geometry," Journal of Mathematics Education, vol. 5, no. 1, pp. 15-33, 2012. Article (CrossRef Link)

[18] L. Orcos, C. Jordan, and A. Magrenan, "3D visualization through the Hologram for the Learning of Area and Volume Concepts," Journal Mathematics, vol. 7, no. 3, 2019. Article (CrossRef Link)

[19] T. G. Kramarenko and O. S. Pylypenko, "Problems of preparation of teacher for implementation of elements STEM-teaching mathematics," Physical and Mathematical Education, vol. 4, no. 18, pp. 90-95, 2018. Article (CrossRef Link)

[20] P. Hewson, "GeoGebra for mathematical statistics," International Journal for Technology in Mathematics Education, vol. 16, no. 4, pp. 169-172, May 2011. Article (CrossRef Link)

[21] E. Angel and D. Shreiner, Interactive Computer Graphics: A Top-Down Approach with WebGL, $7^{\text {th }}$ Edition, Pearson Education Ltd., 2015. Article (CrossRef Link)

[22] M. Hohenwarter, D. Jarvis, and Z. Lavicza, "Linking Geometry, Algebra, and Mathematics Teachers: GeoGebra Software and the Establishment of the International GeoGebra Institute," International Journal for Technology in Mathematics Education: Research Information Ltd., vol. 16, no. 2, pp. 83-86, 2009. Article (CrossRef Link)

[23] F. Botana, Z. Kovacs, A. Martinez-Sevilla, and T. Recio, "Automatically Augmented Reality with GeoGebra," Augmented Reality in Educational Settings, pp. 347-368, 2019. Article (CrossRef Link)

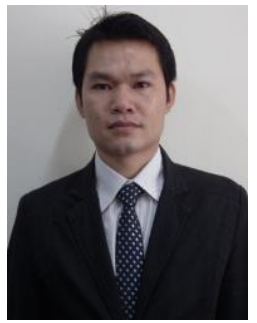

Kalaphath Kounlaxay received the B.S. degree in the Department of Mathematic and Computer Science at National University of Laos, Vientiane, Laos, in 2002. and M.S. degree in the Department of Computer Engineering at Jeonju University, Jeonju, Korea, in 2012. He was a teacher in the Vocational School for the disables, Vientiane, Laos, in 2003 to 2004. He is now a lecturer in Souphanouvong University, Louangprabang, Laos. He is $\mathrm{Ph} . D$. Candidate in the Department of Game Engineering at PaiChai University, Daejeon, Korea. His research interests include computer network, software engineering, computer graphics and multimedia, augmented reality and virtual reality. 

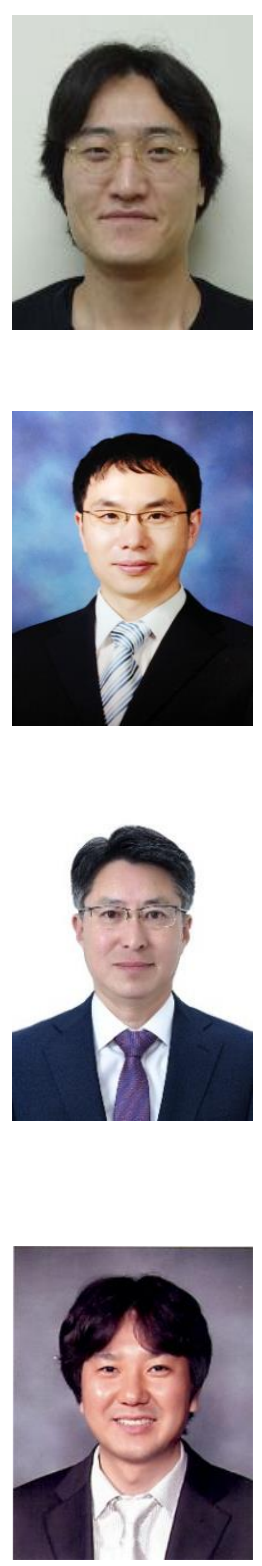

Yoonsik Shim received B.S. degree in Mechanical Engineering and M.S. degree in Computer Science in Korea University. He received Ph.D. Degree in Informatics from University of Sussex, as a member of the Centre for Computational Neuroscience and Robotics. Currently he is an assistance professor in Department of Game Engineering in Paichai University, Daejeon, Korea. His research interests are focused on bio-inspired adaptive robotics, computational neuroscience, chaotic neurodynamics, self-organisation, and evolutionary robotics.

Shin Jin Kang received an MS degree from the Department of Computer Science and Engineering from Korea University in 2003. After graduation, he joined Sony Computer Entertainment Korea as a video game developer. From 2006, He has worked at NCsoft Korea as a lead game designer. He received $\mathrm{PhD}$ degree in Computer Science \& Engineering at Korea University in 2011. He is currently a professor at the school of games in Hongik University.

Ho-Young Kwak received Ph.D. in Computer Science Department of Hong-Ik University, Seoul, Korea, in 1990. He is now a professor at Department of Computer Engineering at Jeju National University, Korea. Dr. Kwak has been served as President of Korea Society of Computer Information.

Soo Kyun Kim received Ph.D. in Computer Science \& Engineering Department of Korea University, Seoul, Korea, in 2006. He joined Telecommunication R\&D center at Samsung Electronics Co., Ltd., from 2006 and 2008. He worked a professor at Department of Game Engineering at Pai Chai University from 2008 to 2020. He is now a professor at Department of Computer Engineering at Jeju National University, Korea. Dr. Kim has published many research papers in international journals and conferences. Dr. Kim has been served as Chairs, program committee or organizing committee chair for many international conferences and workshops; Chair of ICCCT'11, ITCS'10, HumanCom'10, EMC'10, ICA3PP'10, FutureTech'10, ACSA'09, Em-Com'09, CSA'09, CGMS'09, ISA'09, SIP'08, FGCN'08 and so on. Also Dr. Kim is guest editor of the International Journal of "IET Image Processing" and "Multimedia Tools and Applications". His research interests include multimedia, pattern recognition, image processing, mobile graphics, geometric modeling, and interactive computer graphics. He is a member of ACM, IEEE, IEEE CS, KACE, KMMS, KKITS and KIIT. 